\title{
THE 'RECIPROCITY' GAME: A THEORETICAL BASIS FOR MEASURING RECIPROCITY IN HUMAN SOCIO-ECONOMIC INTERACTIONS
}

\author{
ANTONIOS AVGERIS, ACHILLEAS KONTOGEORGOS, PANAGIOTA \\ SERGAKI
}

\begin{abstract}
:
The Theory of Expected Utility is the central theory that describes the way individuals make a decision according to the classical economic theory. Despite the fact of that, experimental studies on individuals' behavioral attitude of the last 20 years have shown that this theory does not accurately represent human behavior from a descriptive point of view. On the contrary, these studies bear out that reciprocity is the motivational drive of human decisions. People have a reciprocal behavior if they praise and repay good deeds and punish unkind ones. On the other hand, they are rational if they make every effort to maximize the benefit and their utility. In this review paper, we present a theoretical framework of reciprocity's measuring through the experimental economics. In particular, we propose an experimental way of identifying the incentives under which the subjects make a decision. Are they motivated by other people's well-being or by material self-interest? For achieving this, Homo Economicus and Homo Reciprocans "conflict" amid two different games of Game Theory. These games (Ultimatum Game and Dictator Game) create a new one, which is called "The Reciprocity Game" and it is going to offer us an important theoretical basis for the empirical measurement of human reciprocity in the future.
\end{abstract}

\section{Keywords:}

Game Theory, Homo Economicus, Homo Reciprocans, Reciprocity, Social Economy

JEL Classification: C72, C90, Z13

\section{Authors:}

ANTONIOS AVGERIS, Aristotle University of Thessaloniki, Greece, Email: antoavge@agro.auth.gr ACHILLEAS KONTOGEORGOS, University of Patras, Greece, Email: akontoge@upatras.gr PANAGIOTA SERGAKI, Aristotle University of Thessaloniki, Greece, Email: gsergaki@auth.gr

\section{Citation:}

ANTONIOS AVGERIS, ACHILLEAS KONTOGEORGOS, PANAGIOTA SERGAKI (2018). The 'Reciprocity' Game: A theoretical basis for measuring reciprocity in human socio-economic interactions. International Journal of Social Sciences, Vol. VII(1), pp. 13-33., 10.20472/SS.2018.7.1.002 


\section{Introduction}

Expected Utility Theory (EUT), constitutes the basis of the economic behavioral theory, according to which, people decide under emergency and uncertainty situations. (Bernoulli, 1954). Despite the fact that this theory is the foundation of decision making theory science, various experimental findings and results of the last decades have externalized a different image of human behavior. Even though this theory is a very important tool of normative behavior, empirical researches have shown that subjects behave in different ways than what this Theory defines. As a result, a number of other behavioral patterns were shown. These theories were called as, "unexpected utility" models. Also, these theories were meant to bring out a different image of human behavior. A more flexible, and psychologically, more logical part of individual selves. (Panas, 2007).

Self-seeking behavior of people is the main basis of economic theory. It treats people as beings who behave completely rationally. Consequently, most of economic models are based on the assumption of rational and selfish agents (Dufwenberg and Kirchsteiger, 2004). In these models motives such as fairness and reciprocity are automatically excluded from human behavior (Fehr, Kirchsteiger and Riedl, 1998). However, unlike the aforementioned, many influential, renowned and well-known economists including Adam Smith (1759), Gary Becker (1974), Kenneth Arrow (1981), Paul Samuelson (1993) and Amartya Sen (1995), have reported and claimed that people often tend to help their fellow human beings and care for their welfare as well, and this maybe have plenty of economic consequences (Fehr and Schmidt, 2006). Nevertheless, most economists still routinely assume that material self-interest, selfishness, and rational and opportunistic individuals' behavior, are only some of the motivations of all people in their daily life (Dufwenberg and Kirchsteiger, 2004).

A large piece of experimental evidence and, in particular, laboratory experiments and field studies indicate that most of individual economic decisions are motivated, on the one hand, by individual and material self-interest but on the other hand by concerns of fairness, altruism and reciprocity. The results of these experiments were the reason for the development of several new economictheoretical models based more on human feelings and less on logic, in terms of human behavior. (Fehr and Gächter, 2000; Sobel, 2005; Fehr and Schmidt, 2006).

Reciprocity is an agent's response to the actions and treatment he receives from another person. This behavioral response includes kindness and unkindness actions (positive or negative reciprocity). An action of kindness can be both distributional fairness or fairness intentions. Numerous experiments and experimental evidence prove that reciprocity is a determining factor in people's behavior, a powerful determinant in people's every day life. Various experiments and questionnaire studies took place by psychologists and economists, as well as, plythora of references and an amazing literature in other sciences such as sociology and anthropology which emphasizes in the omnipresence of reciprocal behavior (Kahneman, Knetsch and Thaler, 1986a; Fehr and Gächter, 2000; Falk and Fischbacher, 2006).

Actually, Maximiano (2012) discovered in a research she was doing for her working paper that, people appear to be very heterogeneous in their preferences. Thus, subjects instead of being motivated only by their personal interest, are concerned about the fairness and the welfare of others and behave with reciprocity, i.e., they are willing to sacrifice some money (utility or usefulness) to reward (or punish) good (or bad) behavior of others with whom transactions are done (Maximiano, 
2012). Especially, if those subjects belong to common groups of people like groups of policy or religion, they tend to help and trust each other and reciprocate favors (Fehr and Falk, 1997). In an overview article, Fehr and Gächter (2000) report that forty to sixty six (40-66\%) percent of subjects display non-selfish behavior. In the context of incomplete contracts it has been shown that reciprocity can serve as a contract enforcement device.

This body of evidence is inextricably and extremely linked with various evidence and experimental findings gathered by scientists including economists and psycologists during the recent past. It indicates that a significant number of people are strongly influenced and motivated by the preferences and choices of others. This indicates that a significant number of people are strongly influenced and motivated by the preferences and choices of others, which implies their concern for well-being, utility and reciprocity in various social interactions between them (Fehr and Schmidt, 2006).

Also, the same experimental economists, based on the results of a survey was conducted by de Waal (1991), report the following:

"[...]that food sharing is a very common phenomenon among chimpanzees. However, chimpanzees do not share food regardless of their past interactions. Sharing of individual $A$ with $B$ is highly positively correlated with sharing of $B$ with $A$. Moreover, if $A$ requests food from $B, B$ is significantly more likely to respond to this request with aggression if $A$ did not share with $B$ in the past. The fact that close neighbors of our evolutionary ancestors behave reciprocally suggests that this behavior has deep evolutionary roots." (Fehr and Schmidt, 2006).

Specifically, in a survey that took place in November 2012 between common chimpanzees and chimpanzees of Bonobos species (Bonobos have $98.7 \%$ common DNA with people, according to Kay Prüfer, a researcher of Max Planck Institute in Germany) (see Prüfer et al., 2012), found that both common chimpanzees as well as Bonobos behaved similar to humans (Kaiser et al., 2012; Proctor et al., 2013).

In contrast to the above, many human subjects respond unkindly if they have been hurt and act accordingly. A reciprocal behavior like that is very often and common, especially among strangers, in one-shot encounters regardless the cost (Fehr and Gächter, 1998).

Since the results of their experiment, Güth, Schmittberger and Schwarze (1982), found that a behavior of negative reciprocity was a very usual and common phenomenon in dozens if not hundreds repetitions of so-called Ultimatum Game. Therefore, during the run of these games the rejection of positive, yet uneven offers, was often among subjects despite the fact that a rejection would be costly for them. In this way the other bargaining party is induced to offer a more equal and also closer to the equal split, payoff (Güth, 1995; Camerer and Thaler, 1995; Roth, 1995; Fehr and Gächter, 1998).

At the same time, the above result comes in a full agreement with the findings of many other experimental economics surveys based on the Ultimatum Game (Güth, Schmittberger and Schwarze, 1982; Thaler, 1988; Güth, 1995; Camerer and Thaler, 1995; Roth, 1995). In addition, if subjects have the chance for sanctioning the second participant of the game, even if it is costly for them, subjects finally sanction defectors (Fehr and Gächter, 2000; Carpenter and Matthews, 2003; Falk and Fischbacher, 2006). 
Furthermore, other types of games like the Dictator Game, played an important role in weakening the exclusive reliance on the self-interest hypothesis. This game is possessed by the simplicity feature that enables the experimenters to undestrand the participants subjects' motives. In fact, in the Dictator Game as well as in all other similar games one player has a strictly dominant strategy if he has a self-interest behavior and this selfish strategy is dominant and understandable in all cases. Therefore, if a player does not follow this strategy, it can be inferred that he did not do it by choice so, we can make assumptions and inferences about his emotional motivations. (Fehr and Schmidt, 2006).

Consequently, the way in which this behavior has to be modeled is still disorganized and unsettled. Textbook theory defines the concept of reciprocity very successfully in case of obtaining a favor from the person to whom reciprocity is directed. However, as far as the kind of reciprocity found in many lab games and field experiments such as Ultimatum and Dictator Game, is impossible to be explained in this way that textbooks suggests. In these games, reciprocity is observed even if the participants are unknown to each other or in one-shot games. Under these circumstances, there is a little chance of returning a favor (Bolton, Brandts and Ockenfels, 1998).

As mentioned at the Abstract, this paper aims to create a theoretical model that can be used in order to measure the reciprocity between human (socio-economic) relations, particularly if people are possessed by reciprocity or opportunism. This theoretical framework will be called "Reciprocity Game" from now on, and it is the result of the sequential execution and implementation of the two well-known games of Game Theory, the Ultimatum Game and the Dictator Game. Thus, in an experimental future survey we could have reliable results and conclusions about the battle between the two kinds of people in experimental economics, Homo Economicus versus Homo Reciprocans. 


\section{Meaning of Reciprocity}

\subsection{Definition of Reciprocity}

For the field of psychology, and in particular for social psychology, reciprocity is a social rule whereby people should repay and return the favors, benefits, or penalties they have received from ther subjects, in the future. Briefly, people reciprocate miscellaneous kinds of treatments each other (Cialdini, 2006).

Also, the researcher, professor and scientist, Robert Keohane (1986), has defined reciprocity as follows:

"Reciprocity refers to exchanges of roughly equivalent values in which the actions of each party are contingent on the prior actions of the others in such a way that good is returned for good, and bad for bad."

However, he also refers in his paper that reciprocity is an ambiguous concept, and that is why each school of thought defines reciprocity in a different way, adapting the definition to its own needs and its own purposes (Keohane, 1986).

\subsection{Norm of Reciprocity}

According to Gouldner (see Couldner, 1960), the norm of reciprocity is a general basic tendency that can be found in most human societies in whole history. Perhaps, this point of view constitutes the most well-known and classical reference (Perugini et al., 2003). This norm requires that a subjects should repay the kind and unkind actions. Particularly, people will respond favorably those who have helped them in the past by returning benefits for benefits, and retaliate against those who have been detrimental with either indifference or hostility to harms (Whatley et al., 1999; Perugini et al., 2003).

In the field of psychology, and especially in social psychology, the concept of reciprocity has been used by many scientists to explain a variety of phenomena. Reciprocity meets in different aspects of everyday life, such as attitude change (Cialdini, Green and Rusch, 1992), intimacy in close relationships (Surra and Longstreth, 1990), interpersonal perception (Kenny et al., 1996), altruism (Krebs, 1975), aggression (Robarchek and Robarchek, 1998), cooperation (Komorita and Parks, 1999), intergroup interactions (Goren and Bornstein, 1999), consumer shopping and behavior (Miller and Kean, 1997), restaurant tipping (Rind and Strohmetz, 1999), and gift giving (Cialdini, 1988). It also has been used in several other sciences and their disciplines and sub-disciplines, like in sociology, sociobiology, economics, political science, anthropology, animal behavior, and evolutionary psychology and biology (Axelrod, 1984; Cosmides and Tooby, 1989; de Waal and Berger, 2000; Fehr, Gachter and Kirchsteiger, 1997; Hoffman, McCabe and Smith, 1998; Nowak and Sigmund, 1998; Trivers, 1971; Wedekind and Milinski, 2000).

At the same time, in many social dilemma conditions, reciprocity has been proved to be a valuable "tool" for explaining patterns of outcomes. Axelrod (1984; Axelrod and Dion, 1988) has shown that the "tit-for-tat" strategy, a reciprocity-based strategy ideated by Anatol Rapoport (1958), can 
guarantee the highest payoff in the long run given certain features of the situations analyzed (Perugini et al., 2003).

Individuals who infringe the norm of reciprocity and do not behave as it defines, i.e., accepting without returning the benefits and goods, are treated as intruders form society and are disliked by the social group (Wedeking and Milinski, 2000). So, that implies that individuals who benefit without helping or contributing something are called as free-riders. The above behavior describes the "freeriding" problem, where the person chooses to cheat the other parts of the transaction, "reaping the fruits" of their labor without contributing to it. This phenomenon is particularly pronounced and acute in collective efforts and in groups of people with common goals, especially, in organizations that aim to make a profit like a company or an agricultural cooperative where dominate the principalagent theory (Sloof et al., 2003). Both individuals and social groups often punish and exclude freerides from a human whole, even if this may be costly and harmful for the group (Carpenter, 2007). Consequently, the agents will adopt the behavior that will lead them to great lengths, avoiding being a moocher, a freeloader, or a ingrate (Cialdini, 2006).

\subsection{Positive and Negative Reciprocity}

During the last fifteen years experimental economists have documented the existence of a class of non-pecuniary motives that have been called "social preferences" (Fehr and Falk, 2002). In behavioral economics, positive and negative reciprocity are modeled as "social preferences" (Cox, Friedman and Gjerstad, 2007; Dufwenberg and Kirchsteiger, 2004; Falk \& Fischbacher 2006; Rabin, 1993). Reciprocity comes in two versions, positive reciprocity and negative reciprocity.

Positive reciprocity, doing something beneficial for someone after being beneficially treated, is more evident when playing gift-exchange games like a sequential prisoner's dilemma. Second players usually tend to be more cooperative and reciprocal when the first players do something similar (Fehr, Kirchsteiger, and Riedl, 1993). Additionally, behavior of positive reciprocity is also the case if a person commit an action that will benefit another, and this action is returned to this person, from the person who received this favor, with approximately equal positive result (Caliendo, Fossen, and Kritikos, 2012; Suranovic, 2001a). For instance, if one takes care of someone else's dog, then the other man will repay this favor with another corresponding action such as a gift with similar value. So, the reciprocated favor or gift should have equal or approximately equal value otherwise an uncomfortable social situation is very likely to happen (Chen, Chen, and Portnoy, 2009). Example of this is that if a man takes care of another person's dog and the other purchases a car in that individual, then the returned gesture does not have the same value as the primary one. In general, individuals expect that actions directed to repayment of other acts or favors should have the same or almost the same value (Suranovic, 2001a).

Negative reciprocity exists when a person who receives a negative action, reciprocates with a same, equal action with negative consequences upon the corresponding agent. If the respondent reaction is not as equal as the original one in negative value and also has negative effects in higher level then it is possible to judged as unfair for the second subject. So, negative reciprocity fairness includes replies and actions with equal negative effects for both parties of interaction something like a "quid pro quo" type of response (Suranovic, 2001b), i.e. in few words, a negative reciprocity behavior is met when a subject responds and reciprocates an action that has negative effects on 
himself to another subject with approximately similar negative effect (Caliendo, Fossen, and Kritikos 2012; Suranovic, 2001b). In experimental economics a behavior of negative reciprocity is a very common practise and strategy during a run of the Ultimatum Game in which the first player proposes a split of an ammount to the second player. The second mover in many occasions rejects this offer in favor of an outcome as the consequence of this both get nothing (Güth, Schmittberger, and Schwarze, 1982). For example, if an individual makes an unjust and violent act against someone else then the victim is expected to do the same and retaliate with a violent behavior, too. However, if the last act is not of equal value to the initial one, then the norm of reciprocity is violated (Chen, Chen, and Portnoy, 2009).

However, in world literature there are many references and various definitions of negative reciprocity depending on the scientific domain for which it is used. In corroboration of this, in cultural anthropology negative reciprocity is defined as the attempt to get something for nothing (Sahlins, 1978).

\subsection{Reciprocal Function}

There are several forms of reciprocal functions. One of them has the form:

$$
y=k / x \text { or } f(x)=k / x
$$

where $k$ is a real number and (because $k / 0$ is undefined). The graph of $y=k / x$ gets closer to the $x$-axis as the value of $x$ increases but it never meets the axis. This is called the horizontal asymptote of the graph. Each piece of the graph also gets closer to the $y$-axis as $x$ gets closer to 0 but it never meets the $y$-axis because there is no value for $y$ when $x=0$. This is called the vertical asymptote of the graph (see fig. 1 below).

Figure 1: Graph of reciprocal function, $f(x)=1 / x$. It is a hyperbola and an odd function.

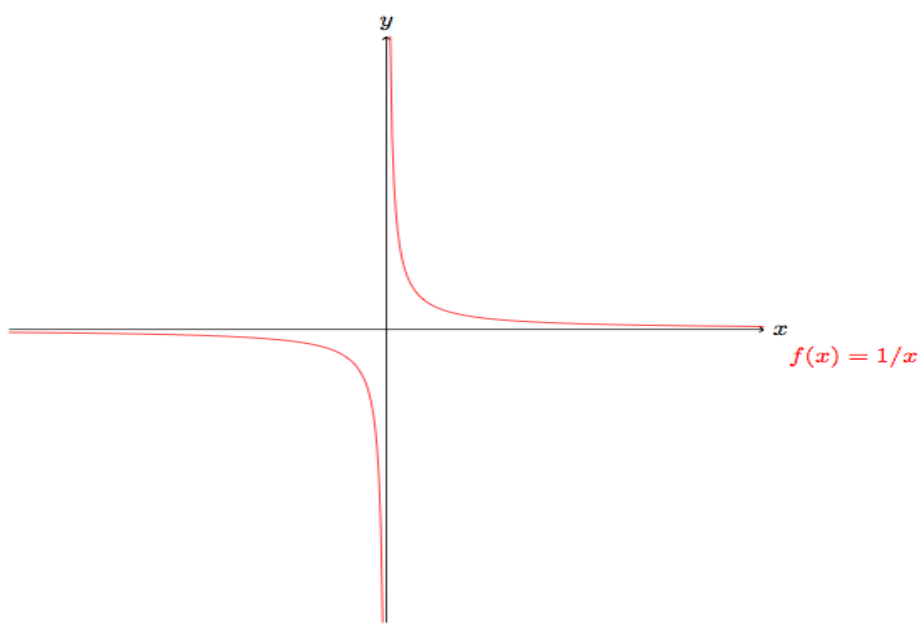

In a different way the domain and range of this reciprocal function can be expressed as follows: 


$$
\begin{aligned}
& \text { Domain }=\{x: x \in R \mid x \neq 0\} \\
& \text { Rage }=\{x: y \in R \mid y \neq 0\}
\end{aligned}
$$

As McCabe, Rigdon and Smith (2003) refers in their paper about the reciprocal behavior:

"The reciprocity-trust hypothesis explains this behavior as a reciprocal-trust relationship between players 1 and 2, who are reciprocal-trust related if: (i) there are mutual gains from their joint actions, (ii) Player 1 takes a risk by trusting Player 2, and (iii) Player 2 gives up something in order to reciprocate Player 1's trust. The mutual gains from the exchange are measured relative to the sub game perfect equilibrium (SPE)".

\section{Homo Economicus}

Economic science conceptualizes human behavior, through the values of Homo Economicus, a consistently rational and in a narrow way self-interested agent whose subjectively-defined ends are optimally pursued. In general, the goal of Homo Economicus is the utility maximizatipn in the consuming procedure and the maximization of profit in the producing behavior (Rittenberg and Trigarthen, 2012). Behavioral economics (the economics of actual human behavior, not excluding general cognitive biases and other irrationalities), and Homo Reciprocans (the human behavior scheme that is based in cooperation rather than antagonism) are standing opposite to Homo Economicus assumptions (Rittenberg and Trigarthen, 2012).

Homo Economicus is assumed to behave total rationally by game theory despite the fact that a relative high number of reciprocal participants in one-shot situations. According to Berg et al. (1995), Gachter and Falk (2002), Miller and Klean (1997), Fehr et al. (1998), Fehr and Falk (1997), Abbink et al. (2000) the percentage of subjects exhibiting reciprocal choices ranges from $40 \%$ to $60 \%$. However, we have to keep in mind that there is an important fraction of subjects who behave totally selfish and do not reciprocate amounting from $20 \%$ to $30 \%$, in the cites mentioned before, which consists a non-trivial selfish minority. This coexistence of selfness and reciprocity raises several questions about the way selfish and reciprocal types interact or about the institutional sides that enhance each of these types. There is a very brief literature concerning the questions above (Fehr and Gachter, 1998).

\section{Homo Reciprocans}

The second kind of economic man who reigns in the science of economics and psychology is the Homo Economicus, an alternative model of economic human existence. Homo Economicus is driven by both reciprocal behavior and reciprocal motives, i.e. he uses the concept of utility value for rewarding or punishing the other subjects (Rabin,1993; Falk and Fischbacher, 2006). Conceptually, someone can identify and distinguish the positive reciprocity from the degree to which a person rewards kind acts while the negative reciprocity from the degree to which he punishes unkind ones (Dohmen et al., 2009).

Some economics theories of human conceptualize Homo Reciprocans, or the human who reciprocates, as actors who cooperate and try to improve their environment, opposing the Homo 
Economicus ideal, which views human exclusively motivated by selfish material (Dohmen et al., 2009).

\section{The Ultimatum Game}

\subsection{Description}

The Ultimatum Game is a very famous game which belongs to the wide scientific field of experimental economics and Game Theory. The first who developed and indroduced it, was Güth and his colleagues (see Güth, Schmittberger and Scharze, 1982).

Andreoni and Blanchard (2006) said the following:

"It has come to symbolize the power of subgame perfection in game theory and its utter failure in practice" (Andreoni and Blanchard, 2006).

From a descriptive point of view the game is played like this; The first mover ("the proposer") receives an ammount of money $=c$ which is fixed, and makes a division of it between himself and the second player. So, he proposes a division $x$ to the second player, where $0 \leq x \leq c$. The second player ("the responder") has two options, either accept or reject this offer. If the responder accepts, the division of the ammount is $c-x$ for the proposer and $x$ for the responder. Therefore, the money is split according to the proposal of the first player. If the responder rejects, both movers get nothing, according to Figure 2(below). The game is typically played only once so that reciprocation is not an issue. Because of this, we combine it with the Dictator Game.

The ultimatum game has been studied intensively in the past, especially during the 80 s and 90 s. See Güth, Schmittberger and Schwarze (1982), Thaler (1988), Güth (1995), Camerer and Thaler (1995), and Roth (1995). The results of subject behaviors can be summarized as follows:

i. practically no offers exceed the half of the amount,

ii. the modal offers lie in a range between $40 \%$ and $50 \%$,

iii. offers below $20 \%$ of the available amount are extremely rare,

iv. whereas offers close to $50 \%$ are practically never rejected, the rejection rate for offers below $20 \%$ is rather high.

(Falk and Fischbacher, 2006) 
Figure 2: Tree form of the Ultimatum Game

\subsection{Nash Equilibrium}

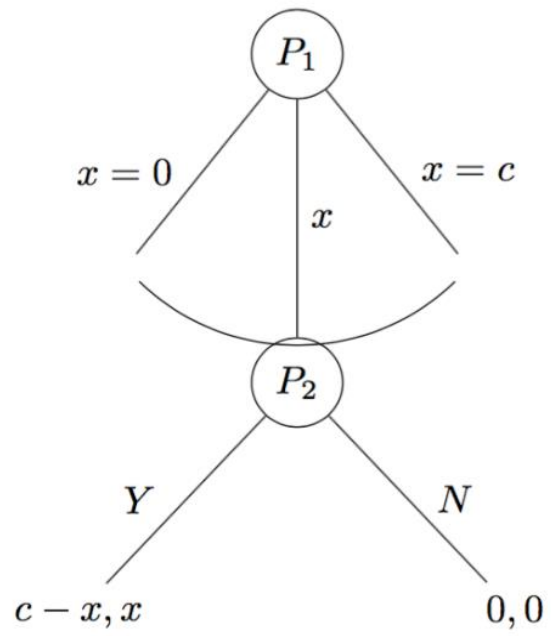

Suppose that there is a sum of money equal to $c$. The first mover ("the proposer") makes a proposed division $x$ of the amount he will offer in the interval $[0, c]$, the second mover then is going to receive $x$ offered by the first player and the first will receive the division $c-x$ of the total available endowment. The second player have to choose some function $f:[0, c] \rightarrow\{$ "accept, "reject" $\}$ (i.e. the second chooses which division to accept and which to reject). So, the strategy profile is represented as $(x, f)$, where $x$ is the proposal made by the first player and $f$ is the function. If $f(x)=$ "accept" the first player ends up with $c-x$ and the second with $x$, otherwise neither get something.

So, $(x, f(x))$ is a combination of points that creates a Nash equilibrium in the ultimatum game. If $f(x)=$ "accept" and there is no $y>x$ such that $f(y)="$ accept" (i.e. the second mover (the responder) is going to reject all divisions in which player 1 keeps more than $c-x$ for himself). Therefore, in accordance with the above mentioned, the first player is not willing to attempt an increase in the percentage of the pie he will retain for himself because the second player is not going to accept a lower-level offer than $x$. So, the first player does not wish to increase his/her own demand amount of money since the second player will reject any higher demand. On the other hand, the responder (second mover) does not want a rejection of a demand because (s)he would not get something then.

Also, there is one other point that satisfies Nash equilibrium requirements where $c-x=x$ and $f(y)=$ "reject" for all $y>0$ (i.e. finally, the second player would reject any demand of money that gives the first any amount of the total). In this case, neither the first nor the second player get something, but both of them could get nothing too, if they do not change their strategy at the same time. 
Nevertheless, only one of these two equilibrium situations satisfies a more realistic concept of this, i.e. a sub-game perfect Nah equilibrium. Suppose, that the first player divides a small payoff to the second player while (s)he demands a large one for himself. By rejecting this offer, the second gets nothing rather than something. So, the best choice for the second mover is to accept any part of the total pie that is given by the first player. If this is known by the first player, then $\mathrm{s}(\mathrm{he})$ will offer as small amount as possible (non-zero) to the second.

\section{The Dictator Game}

\subsection{Description}

Similar to the Ultimatum game, is the Dictator Game which also belongs to the field of experimental economics. The first who applied this game were Daniel Kahneman and his colleagues (see Kahneman, Knetsch and Thaler, 1986b). The aim of this game is to offer in world literature a large body of evidence about the rational and selfish man. However, nowadays, various experimental results and findings are in contrast with rationally self-interested individual, known as Homo Economicus (Levitt and Dubner, 2010). However, many researchers and especial some economists are opposed to them and so this evidence is controversial (Bardsley, 2007).

In the Dictator Game, the first mover (the "dictator"), decides and determines (not proposes, like Ultimatum Game) the way he will divide an endowment (such as a sum of money) between himself and a counterpart. The recipient, now, (the second player) just takes the piece of the endowment given by the dictator. Suppose that $c$ is a sum of money and $x$ the recipient's share which is $0 \leq x \leq c$. So, the partition of the amount is $x$ for the first player and $c-x$ for the second mover. In conclusion, the recipient has an entirely passive role because in fact he does not participate in the final contribution of the game at all (Figure 3, below).

According to the Game Theory literature, a game is a proper game if and only if one player's outcome is influenced by the decisions, choices and outcome of at least one other player. In contrast of the above, the Dictator Game does not meet these requirements because the outcome of the game is the result of the choices of the first mover (the dictator). Despite this formal point, the Dictator Game is widely accepted and used by the scientific community as a degenerate game to draw useful conclusions and findings for the two types of economic man, Homo Economicus and 
Homo Reciprocans, i.e. if individuals were only worried about their personal interest or about other's well-being. If the latter is not true then the dictators will keep the entire amount for themselves.

The dictator game has been studied a lot in the past by many researchers, e.g., by Forsythe et al. (1994), Hoffman et al. (1996), and Eckel and Grossman (1998). The stylized facts can be summarized as follows.

i. Offers larger than half of the amount, $x>1 / 2$, are practically never observed,

ii. Roughly $80 \%$ of the offers are between zero and half of the available amount, $0<x \leq 1 / 2$,

iii. About $20 \%$ of the offers are zero.

(Falk and Fischbacher, 2006)

Figure 3. Tree Form of the Dictator Game

Where: $0 \leq x \leq c$

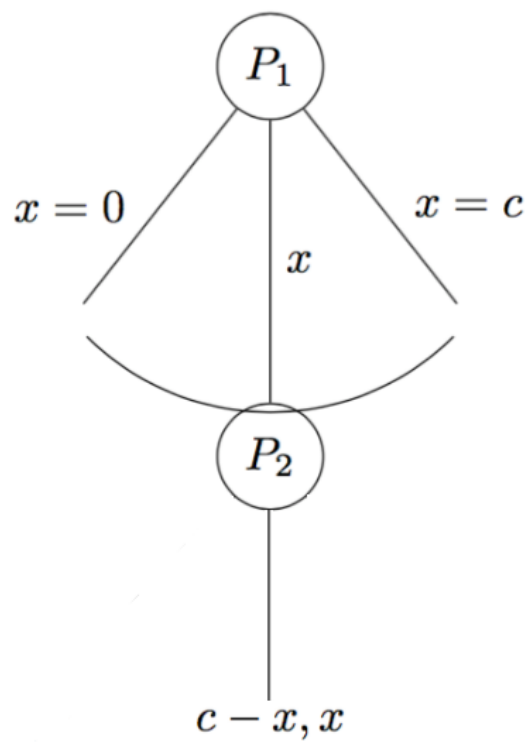

\subsection{Explanatory Approaches}

The hypothesis that both results and findings of the experimental runs of the Dictator Game indicate the existence of rational and opportunism behavior among subjects is not widely acceptable by many scientists. There are experimental indications that support both the classical economic theory of utility maximization and the notable exception that was the reason for creating new holistic economic models that concerned human choices. Some authors argue that giving in the Dictator Game does not mean that he has an altruistic behavior trying to maximize his neighbor's usefulness. On the contrary, they believe that by adopting this behavior, the agents have some negative utility and are also possessed by the feeling of greed thus avoiding the judgment by the experimenter (Bolton et al., 1998). In order to check the aforementioned assumptions, some surveys have been carried out with mixed and diverse results (Hoffman et al., 1994; Bolton et al., 1998). 


\section{The "Reciprocity Game"}

The "Reciprocity Game" constitutes in fact a consolidation and a interaction between the two, already known, games of experimental economy and Game Theory. Ultimatum Game and Dictator Game (figure.4, bellow). The first followed by the second and with this way we take a framework (theoretical or/and empirical) of measuring the reciprocity.

Beginning the "Reciprocity Game" by the implementation of the Ultimatum Game, the first player (P1) make an offer to the second mover (P2) form a sum of money (s)he received. The second mover now have to decide either accept or reject this division of the amount. If the second accepts then (s)he receives the money is offered from the first player, in different way, if the second rejects, neither gets something.

After that, the second player of the previous round becomes the Dictator (the first player in this round) in order to determines the way how the same sum of money is going to split. In both rounds, both players start with the same amount of money and are paired anonymously.

During the recent past, there are few papers that are based on measurement of reciprocity and fairness by combining the Ultimatum Game and the Dictator Game (Forsythe et al. 1994). Nevertheless, there is no paper which integrate these two games as one, called "Reciprocity Game". However, Perugini et al. (2003) also called a combination of two games as "Reciprocity Game". In this case, the situation was modeled as a game, consisting of a Prisoner's Dilemma followed by a Dictator Game.

Figure 4. Tree Form of the "Reciprocity Game". The combination of the Ultimatum and the Dictator Game

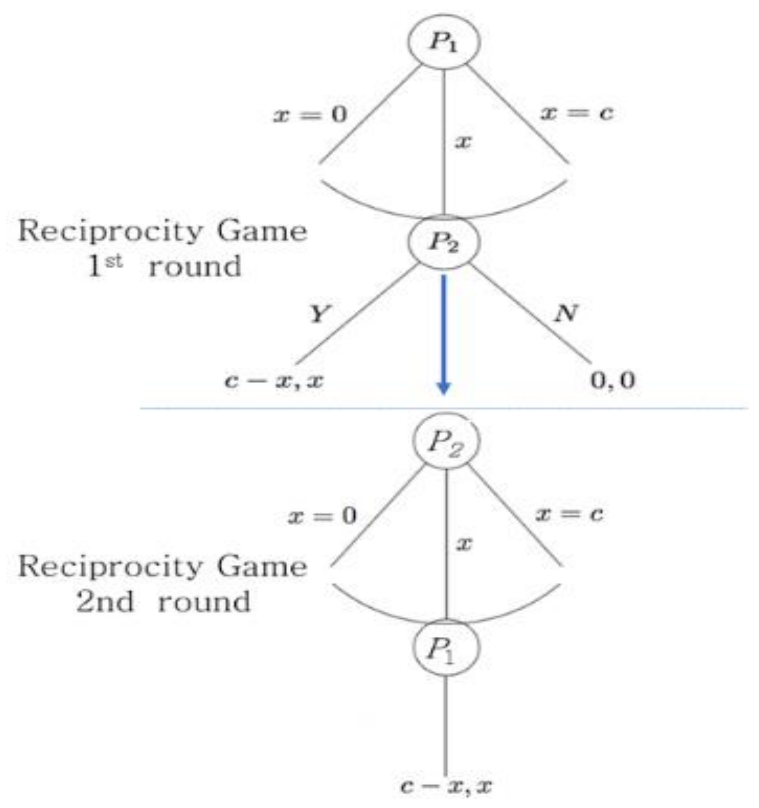




\section{Utility Function in Altruistic and Selfish Behavior}

The combination of the altruist and selfish agent maybe consists the most common one, between the different types of subjects that someone can find in the society, about giving and receiving motivations. Consequently, the altruistic person is motivated to offer more than to take. In contrast, selfish person acts in a different way as it is possessed by low needs to give to others and high needs to receive from others. (Freeman, 2011).

\subsection{The Altruist Man}

Since the above, the altruist's utility function can be written as:

$U^{A}=f\left(X_{1}^{A}, \ldots, X_{n}^{A}\right)+g\left(X_{1}^{A S T}, \ldots, X_{n}^{A S T}\right)$

where $\left(X_{1}^{A}, \ldots, X_{n}^{A}\right)$ is the quantity of goods that altruist keeps for himself, while $\left(X_{1}^{A S T}, \ldots, X_{n}^{A S T}\right)$ is the quantity of goods transferred to the selfish individual from the altruist (Freeman, 2011).

\subsection{The Selfish Man}

During the analyze of selfish man utility function, the most important thing for this personality type of human is to identify the level of importance for him, not so much about the goods he has but the fact that these goods were received by someone else.

So, the selfish individual's utility function has the below form:

$$
U^{S}=F\left(X_{1}^{S}, \ldots, X_{n}^{S}\right)+H\left(X_{1}^{S T}, \ldots, X_{n}^{S T}\right)
$$

where $\left(X_{1}^{S}, \ldots, X_{n}^{S}\right)$ denotes the quantity of his own goods which were not received in the form of a transfer, and $\left(X_{1}^{S T}, \ldots, X_{n}^{S}\right)$ denotes the quantity of goods that are received by him in the form of a transfer from the altruist (Freeman, 2011).

\subsection{The "Reciprocity Game" Utility Function}

$U i, j\left(y, b i, j^{\prime \prime}, b i, j^{\prime}\right)=\mu i, j(y)$

Let $i, j \in\{1,2\}$ be the players of the game

Let $y$ be the total number of the nodes in the game.

Let $b i$ be a behavior strategy, $b i^{\prime}$ the first-priority belief of the one player against the behavior strategy of the other player and $b i "$ the second-order belief of each player, respectively.

Let $\mu i(y)$ the material payoff of each player, depending on the strategic options of the opponent player. 


\section{Conclusion}

Generally, there are plethora of reports, reviews and papers proving the existence both of Homo Economicus and Homo Reciprocans in the real world. Hundreds of experiments have been made at times and the findings of these vary. In essence, the battle between reciprocity and opportunism, i.e., free-riding phenomenon, has not highlighted a winner yet, for which type of behavior people are motivated to adopt.

For the aforementioned reason, the "Reciprocity Game" aims to provide answers and reliable results on human behavior. An important tool to achieve this is the utility function that combines the decisions and strategies of both players as well as their final material payoffs.

So, the purpose of this review paper is through the creation of theoretical model and the "Reciprocity Game", which constitutes the combination of above games, to lay the bases for the measurement of reciprocity in people's economic transactions with experimental way in the future. In this way, we are going to get reliable results and conclusions about the existence or not of the selfish man or Homo Economicus, as it called in economic language. These people have an absolutely rational behavior away from emotions and feelings. In other words, the "Reciprocity Game" will produce useful data about individuals' economic behavior, either those people who care for their prosperity and satisfaction acting as utility maximizers and thus contribute to a worsening of free-riders problem or those who are interested in fellowmen's welfare.

\section{Acknowledgements}

Authors would like to thank the reviewers for their helpful and valuable comments, which have enhanced the quality of the paper but more specifically to express their warmest gratitude to Mrs. Avgeri Elpida for the valuable language help and proof reading the article. Elpida holds a M.Ed. and a M.Soc.Sc. in International and Comparative Education from Stockholm University while she received her Bachelor's degree from Aristotle University of Thessaloniki in English Language and Literature. Nowadays, she is working as educator in an English International School in Stockholm.

\section{References}

Abbink, K., Irlenbusch, B. and Renner, E. (2000). The moonlighting game. Journal of Economic Behavior \& Organization, 42(2), pp.265-277. https://doi.org/10.1016/S0167-2681(00)00089-5

Andreoni, J. and Blanchard, E. (2006). Testing subgame perfection apart from fairness in ultimatum games. Experimental Economics, 9(4), pp.307-321. https://doi.org/10.1007/s10683-006-0064-7

Axelrod, R. (1984). The evolution of cooperation. New York: Basic Books.

Axelrod, R. and Dion, D. (1988). The Further Evolution of Cooperation. Science, 242(4884), pp.1385-1390. https://doi.org/10.1126/science.242.4884.1385 
Arrow, K. (1981). Optimal and Voluntary Income Redistribution. In: S. Rosefielde, ed., In Economic Welfare and the Economics of Soviet Socialism: Essays in Honor of Abram Bergson, 1st ed. Cambridge: Cambridge University Press, pp.267-288. https://doi.org/10.1017/CBO9780511895821.012

Bardsley, N. (2007). Dictator game giving: altruism or artefact?. Experimental Economics, 11(2), pp.122-133. https://doi.org/10.1007/s10683-007-9172-2

Becker, G. (1974). A Theory of Social Interaction. Journal of Political Economy, 82(6), pp. 1063-1093. https://doi.org/10.1086/260265

Berg, J., Dickhaut, J. and McCabe, K. (1995). Trust, Reciprocity, and Social History. Games and Economic Behavior, 10(1), pp.122-142. https://doi.org/10.1006/game.1995.1027

Bernoulli, D. (1954). Exposition of a New Theory on the Measurement of Risk. Econometrica, 22(1), p.23. https://doi.org/10.2307/1909829

Bolton, G., Brandts, J. and Ockenfels, A. (1998). Measuring motivations for the reciprocal responses observed in a simple dilemma game. Experimental Economics, 1(3), pp.207-219. https://doi.org/10.1023/A:1009951108693

Caliendo, M., Fossen, F. and Kritikos, A. (2012). Trust, positive reciprocity, and negative reciprocity: Do these traits impact entrepreneurial dynamics?. Journal of Economic Psychology, 33(2), pp.394-409. https://doi.org/10.1016/j.joep.2011.01.005

Camerer, C. and Thaler, R. (1995). Anomalies: Ultimatums, Dictators and Manners. Journal of Economic Perspectives, 9(2), pp.209-219. https://doi.org/10.1257/jep.9.2.209

Carpenter, J. (2007). Punishing free-riders: How group size affects mutual monitoring and the provision of public goods. Games and Economic Behavior, 60(1), pp.31-51. https://doi.org/10.1016/j.geb.2006.08.011

Carpenter, J. and Matthews, P. (2003). Social reciprocity. Working paper series, No. 1347. Institute for the Study of Labor (IZA).

Chen, Y., Chen, X. and Portnoy, R. (2009). To whom do positive norm and negative norm of reciprocity apply? Effects of inequitable offer, relationship, and relational-self orientation. Journal of Experimental Social Psychology, 45(1), pp.24-34. https://doi.org/10.1016/j.jesp.2008.07.024

Cialdini, R. (1988). Influence: Science and practice. Gleview, IL: Scott, Foresman

Cialdini, R. (2009). Influence. New York: HarperCollins e-books.

Cialdini, R., Green, B. and Rusch, A. (1992). When tactical pronouncements of change become real change: The case of reciprocal persuasion. Journal of Personality and Social Psychology, 63(1), pp.30-40. https://doi.org/10.1037/0022-3514.63.1.30

Cosmides, L. and Tooby, J. (1989). Evolutionary psychology and the generation of culture, part II. Ethology and Sociobiology, 10(1-3), pp.51-97. https://doi.org/10.1016/0162-3095(89)90013-7 
Cox, J., Friedman, D. and Gjerstad, S. (2007). A tractable model of reciprocity and fairness. Games and Economic Behavior, 59(1), pp.17-45. https://doi.org/10.1016/j.geb.2006.05.001

de Waal, F. (1991). The Chimpanzee's Sense of Social Regularity and Its Relation to the Human Sense of Justice. American Behavioral Scientist, $\quad 34(3), \quad$ pp.335-349. https://doi.org/10.1177/0002764291034003005

de Waal, F. B. M. and Berger L. B. (2000). Payment for Labor in Monkeys. Nature, 404(6778), p.563. https://doi.org/10.1038/35007138

Dohmen, T., Falk, A., Huffman, D. and Sunde, U. (2009). Homo Reciprocans: Survey Evidence on Behavioural Outcomes. The Economic Journal, 119(536), pp.592-612. https://doi.org/10.1111/j.14680297.2008.02242.x

Dufwenberg, M. and Kirchsteiger, G. (2004). A theory of sequential reciprocity. Games and Economic Behavior, 47(2), pp.268-298. https://doi.org/10.1016/j.geb.2003.06.003

Eckel, C. and Grossman, P. (1998). Are Women Less Selfish Than Men?: Evidence From Dictator Experiments. The Economic Journal, 108(448), pp.726-735. https://doi.org/10.1111/1468-0297.00311

Falk, A. and Fischbacher, U. (2006). A theory of reciprocity. Games and Economic Behavior, 54(2), pp.293315. https://doi.org/10.1016/j.geb.2005.03.001

Fehr, E. and Falk, A. (2002). Psychological foundations of incentives. European Economic Review, 46(4-5), pp.687-724. https://doi.org/10.1016/S0014-2921(01)00208-2

Fehr, E. and Falk, A. (1997). Reciprocity in experimental markets. In: C. Plott and V. Smith, ed., Handbook of Experimental Economics Results. Amsterdam: North Holland Publications Co., pp.325-334.

Fehr, E. and Gächter, S. (2000). Fairness and Retaliation: The Economics of Reciprocity. Journal of Economic Perspectives, 14(3), pp.159-182. https://doi.org/10.1257/jep.14.3.159

Fehr, E. and Gächter, S. (1998). Reciprocity and economics: The economic implications of Homo Reciprocans. European Economic Review, 42(3-5), pp.845-859. https://doi.org/10.1016/S00142921(97)00131-1

Fehr, E., Gachter, S. and Kirchsteiger, G. (1997). Reciprocity as a Contract Enforcement Device: Experimental Evidence. Econometrica, 65(4), pp.833-860. https://doi.org/10.2307/2171941

Fehr, E., Kirchler, E., Weichbold, A. and Gächter, S. (1998). When Social Norms Overpower Competition: Gift Exchange in Experimental Labor Markets. Journal of Labor Economics, 16(2), pp.324-351. https://doi.org/10.1086/209891

Fehr, E., Kirchsteiger, G. and Riedl, A. (1993). Does Fairness Prevent Market Clearing? An Experimental Investigation. The Quarterly Journal of Economics, 108(2), pp.437-459. https://doi.org/10.2307/2118338 
Fehr, E., Kirchsteiger, G. and Riedl, A. (1998). Gift exchange and reciprocity in competitive experimental markets. European Economic Review, 42(1), pp.1-34. https://doi.org/10.1016/S0014-2921(96)000517

Fehr, E. and Scmidt, K. (2006). The Economics of Fairness, Reciprocity and Altruism - Experimental Evidence and New Theories. In: S. Kolm and M. Mercier Ythier, ed., Handbook of the Economics of Giving, Altruism and Reciprocity. Amsterdam: North Holland Publication Co, pp.615-691. https://doi.org/10.1016/S1574-0714(06)01008-6

Forsythe, R., Horowitz, J., Savin, N. and Sefton, M. (1994). Fairness in Simple Bargaining Experiments. Games and Economic Behavior, 6(3), pp.347-369. https://doi.org/10.1006/game.1994.1021

Freeman, K. (2011). Human needs and utility maximization. International Journal of Social Economics, 38(3), pp.224-236. https://doi.org/10.1108/03068291111105174

Gachter, S. and Falk, A. (2002). Reputation and Reciprocity: Consequences for the Labour Relation. Scandinavian Journal of Economics, 104(1), pp.1-26. https://doi.org/10.1111/14679442.00269

Goren, H. and Bornstein, G. (2000). The Effects of Intragroup Communication on Intergroup Cooperation in the Repeated Intergroup Prisoner's Dilemma (IPD) Game. Journal of Conflict Resolution, 44(5), pp.700-719. https://doi.org/10.1177/0022002700044005007

Gouldner, A. (1960). The Norm of Reciprocity: A Preliminary Statement. American Sociological Review, 25(2), p.161-178. https://doi.org/10.2307/2092623

Güth, W. (1995). On ultimatum bargaining experiments - A personal review. Journal of Economic Behavior \& Organization, 27(3), pp.329-344. https://doi.org/10.1016/0167-2681(94)00071-L

Güth, W., Schmittberger, R. and Schwarze, B. (1982). An experimental analysis of ultimatum bargaining. Journal of Economic Behavior \& Organization, 3(4), pp.367-388. https://doi.org/10.1016/0167-2681(82)90011-7

Hoffman, E., McCabe, K. and Smith, V. (1998). Behavioral foundations of reciprocity: experimental economics and evolutionary psychology. Economic Inquiry, 36(3), pp.335-352. https://doi.org/10.1111/j.1465-7295.1998.tb01719.x

Hoffman, E., McCabe, K. and Smith, V. (1996). Social Distance and Other-Regarding Behavior in Dictator Games. American Economic Review, 86(3), pp.653-660.

Hoffman, E., McCabe, K., Shachat, K. and Smith, V. (1994). Preferences, Property Rights, and Anonymity in Bargaining Games. Games and Economic Behavior, 7(3), pp.346-380. https://doi.org/10.1006/game.1994.1056

Huck, S. and Oechssler, J. (1999). The Indirect Evolutionary Approach to Explaining Fair Allocations. Games and Economic Behavior, 28(1), pp.13-24. https://doi.org/10.1006/game.1998.0691 
Kahneman, D., Knetsch, L. J. Thaler H. R. (1986a). Fairness as a constraint on profit seeking: entitlements in the market. The American Economic Review, 76(4), pp.728-741.

Kahneman, D., Knetsch, J. and Thaler, R. (1986b). Fairness and the Assumptions of Economics. The Journal of Business, 59(4), pp.285-300. https://doi.org/10.1086/296367

Kaiser, I., Jensen, K., Call, J. and Tomasello, M. (2012). Theft in an ultimatum game: chimpanzees and bonobos are insensitive to unfairness. Biology Letters, 8(6), pp.942-945. https://doi.org/10.1098/rsbl.2012.0519

Kenny, D., Bond, C., Mohr, C. and Horn, E. (1996). Do we know how much people like one another?. Journal of Personality and Social Psychology, 71(5), pp.928-936. https://doi.org/10.1037/0022-3514.71.5.928

Keohane, R. (1986). Reciprocity in International Relations. International Organization, 40(1), pp.1-27. https://doi.org/10.1017/S0020818300004458

Komorita, S. and Parks, C. (1999). Reciprocity and cooperation in social dilemmas: review and future directions. In: D. Budescu, I. Erev and R. Zwick, ed., Games and Human Behavior: Essays in Honor of Amnon Rapoport. Mahwah, NJ, US: Lawrence Erlbaum Associates Publishers, pp.315-330.

Krebs, D. (1975). Empathy and altruism. Journal of Personality and Social Psychology, 32(6), pp.1134-1146. https://doi.org/10.1037/0022-3514.32.6.1134

Levitt, S. and Dubner Stephen J. (2010). SuperFreakonomics. [Milano]: Sperling \& Kupfer.

McCabe, K., Rigdon, M. and Smith, V. (2003). Positive reciprocity and intentions in trust games. Journal of Economic Behavior \& Organization, 52(2), pp.267-275. https://doi.org/10.1016/S0167-2681(03)000039

Maximiano, S. (2012). Measuring reciprocity: Do survey and experimental data correlate?. Working Paper. Prurdue University - Department of Economics - Krannert School of Management.

Miller, N. and Kean, R. (1997). Reciprocal exchange in rural communities: Consumers' inducements to inshop. Psychology and Marketing, 14(7), pp.637-661. https://doi.org/10.1002/(SICl)15206793(199710)14:7<637::AID-MAR1>3.0.CO;2-H

Nowak, M. and Sigmund, K. (1998). Evolution of indirect reciprocity by image scoring. Nature, 393(6685), pp.573-577. https://doi.org/10.1038/31225

Panas, E. (2007). Experimental Economics: An Empirical Analysis. SPOUDAI, 83(2), pp.89-105.

Perugini, M., Gallucci, M., Presaghi, F. and Ercolani, A. (2003). The personal norm of reciprocity. European Journal of Personality, 17(4), pp.251-283. https://doi.org/10.1002/per.474

Proctor, D., Williamson, R., de Waal, F. and Brosnan, S. (2013). Chimpanzees play the ultimatum game. Proceedings of the National Academy of Sciences, 110(6), pp.2070-2075. https://doi.org/10.1073/pnas.1220806110 
Prüfer, K., Munch, K., Hellmann, I., Akagi, K., Miller, J., Walenz, B., Koren, S., Sutton, G., Kodira, C., Winer, R., Knight, J., Mullikin, J., Meader, S., Ponting, C., Lunter, G., Higashino, S., Hobolth, A., Dutheil, J., Karakoç, E., Alkan, C., Sajjadian, S., Catacchio, C., Ventura, M., Marques-Bonet, T., Eichler, E., André, C., Atencia, R., Mugisha, L., Junhold, J., Patterson, N., Siebauer, M., Good, J., Fischer, A., Ptak, S., Lachmann, M., Symer, D., Mailund, T., Schierup, M., Andrés, A., Kelso, J. and Pääbo, S. (2012). The bonobo genome compared with the chimpanzee and human genomes. Nature, 486(7404), pp.527531. https://doi.org/10.1038/nature11128

Rabin, M. (1993). Incorporating fairness into game theory and economics. The American Economic Review, 83(5), pp. 1281-1302.

Rapoport, A. (1958). Nets with reciprocity bias. The Bulletin of Mathematical Biophysics, 20(3), pp.191-201. https://doi.org/10.1007/BF02478298

Rind, B. and Strohmetz, D. (1999). Effect on Restaurant Tipping of a Helpful Message Written on the Back of Customers' Checks. Journal of Applied Social Psychology, 29(1), pp.139-144. https://doi.org/10.1111/j.1559-1816.1999.tb01378.x

Rittenberg, L. and Trigarthen, T. (2012). Principles of Microeconomics. Minesota: University of Minnesota Libraries Publishing.

Robarchek, C. and Robarchek, C. (1998). Reciprocities and realities: World views, peacefulness, and violence among Semai and Waorani. Aggressive Behavior, 24(2), pp.123-133. https://doi.org/10.1002/(SICI)1098-2337(1998)24:2<123::AID-AB3>3.0.CO;2-N

Roth, A. (1995). Bargaining experiments. In: J. Kagel and A. Roth, ed., Handbook of Experimental Economics. Princeton: Princeton University Press, pp.253-348.

Sahlins, M. (1978). Stone age economics. London: Tavistock.

Samuelson, P. (1993). Altruism as a Problem Involving Group versus Individual Selection in Economics and Biology. American Economic Review, 83(2), pp.143-148.

Sen, A. (1995). Moral Codes and Economic Success. In: S. Brittan and A. Hamlin, ed., Market Capitalism and Moral Values, 1st ed. Aldershot: Edward Eldar Publishing, pp.23-34.

Sloof, R., Leuven, E., Oosterbeek, H. and Sonnemans, J. (2003). An Experimental Comparison of Reliance Levels under Alternative Breach Remedies. The RAND Journal of Economics, 34(2), pp.205-222. https://doi.org/10.2307/1593714

Smith, A. (1759). The Theory of Moral Sentiments. London: Library of Economics and Liberty. https://doi.org/10.1093/oseo/instance.00042831

Sobel, J. (2005). Interdependent Preferences and Reciprocity. Journal of Economic Literature, 43(2), pp.392436. https://doi.org/10.1257/0022051054661530

Suranovic, S. (2001a). Trade: Chapter 125-7: Positive Reciprocity. [online] Internationalecon.com. Available at: http://internationalecon.com/Trade/Tch125/T125-7.php [Accessed 5 Jul. 2017]. 
Suranovic, S. (2001b). Trade: Chapter 125-8: Negative Reciprocity. [online] Internationalecon.com. Available at: http://internationalecon.com/Trade/Tch125/T125-8.php [Accessed 5 Jul. 2017].

Surra, C. and Longstreth, M. (1990). Similarity of outcomes, interdependence, and conflict in dating relationships. Journal of Personality and Social Psychology, 59(3), pp.501-516. https://doi.org/10.1037/0022-3514.59.3.501

Thaler, R. (1988). Anomalies: The Ultimatum Game. Journal of Economic Perspectives, 2(4), pp.195-206. https://doi.org/10.1257/jep.2.4.195

Trivers, R. (1971). The evolution of reciprocal altruism. Quarterly Review of Biology, 46(1), pp.35-57. https://doi.org/10.1086/406755

Wedekind, C. (2000). Cooperation Through Image Scoring in Humans. Science, 288(5467), pp.850-852. https://doi.org/10.1126/science.288.5467.850

Whatley, M., Webster, J., Smith, R. and Rhodes, A. (1999). The Effect of a Favor on Public and Private Compliance: How Internalized is the Norm of Reciprocity?. Basic and Applied Social Psychology, 21(3), pp.251-259. https://doi.org/10.1207/S15324834BASP2103_8 